\title{
Knowledge, Attitude, and Preventive Practices toward COVID-19 among Bangladeshi Internet Users
}

\author{
Abdur Rahman ${ }^{1 *}$, Nusrat Jahan Sathi ${ }^{1}$ \\ ${ }^{1}$ Researcher, Statistics Discipline, Khulna University, Khulna-9208, BANGLADESH \\ *Corresponding Author: akashrahman32@gmail.com \\ Citation: Rahman A, Sathi NJ. Knowledge, Attitude, and Preventive Practices toward COVID-19 among Bangladeshi Internet Users. Electron J Gen \\ Med. 2020;17(5):em245. https://doi.org/10.29333/ejgm/8223
}

\begin{tabular}{lll}
\hline ARTICLE INFO & ABSTRACT \\
\cline { 1 - 1 } $\begin{array}{l}\text { Received: } 18 \text { Apr. 2020 } \\
\text { Accepted: } 27 \text { Apr. 2020 }\end{array}$ & $\begin{array}{l}\text { Introduction: The COVID-19 is currently the most horrible issue around the world as there is no proven vaccine or } \\
\text { medine for this rapidly spreading disease. The only way left to this situation is to slow down or eradicate the } \\
\text { spreading by adopting preventing measures. }\end{array}$
\end{tabular}

Objective: The purpose of the study is to investigate the knowledge, attitude, and preventive practices toward COVID-19 among Bangladeshi internet users.

Material and Methods: A total of 441 respondents voluntarily participated in a web-based cross-sectional survey. A structured questionnaire was created using Google Forms and the link was shared through authors' networks. Collected information was analyzed using univariate, bivariate, and multivariate techniques.

Results: Respondent of age 30 and above are more optimistic (Adjusted Odds Ratio [AOR] $=1.96,95 \%$ Confidence Interval [Cl], 1.13 to $3.41 ; \mathrm{P}=0.016)$ compared to respondent of age 18-29. For 1 unit change in the knowledge score the likelihood of staying home and wearing mask increases by $1.73(95 \% \mathrm{Cl}, 1.43$ to $2.09 ; \mathrm{P}<0.01)$ and $1.54(95 \% \mathrm{Cl}$, 1.25 to $1.77 ; \mathrm{P}<0.01$ ) times respectively. From the linear regression analysis, we see that urban residence type (vs. rural, $\beta=0.274 ; P=0.024)$ are significantly associated with higher knowledge scores. Additionally, a significant positive correlation exists between the COVID-19 knowledge score and the preventive practice score $(r=0.291, P$ $<0.01$ ).

Conclusion: Although knowledge and preventive practices among Bangladeshi internet users are encouraging, this study suggests updated knowledge be provided by healthcare authorities to enhance appropriate preventive practices throughout the COVID-19 outbreak.

Keywords: COVID-19, knowledge, attitude, preventive practice

\section{INTRODUCTION}

Novel coronavirus disease 2019 (COVID-19) is the most recent contagious respiratory infectious disease $(1,2)$ which has created a massive disaster in human life worldwide. COVID19 holds the same veiled RNA structure resembling SARS-CoV and MERS-CoV but it is more pestiferous (3-5). The basic idea about COVID-19 infection is that it spreads through the direct mucus contact with the breath/ingestion/salivary abscess of an infected person that can live on hands, objects or surfaces in the past nine days $(6,7)$.

COVID-19 is originated from the Hunan seafood wholesale market, Wuhan, Hubei state, China in late December 2019 (2). The infection started from Asia soon expanded rapidly around the world $(1,8)$, which lead World Health Organization (WHO) and the Public Health Emergency of International Concern (PHEIC) to declare COVID-19 as an emergency on January 30, 2020 , and formally proclaimed it as an epidemic on March 11 , $2020(9,10)$.

The infection has outreached a total of 210 countries or regions where the total confirmed number of cases is over 1.86 million, $3.85 \%$ of the active patients are critically ill and over 1 lakh death already reported due to COVID-19 until April 13, 2020 (11). Like all other countries, Bangladesh is also at the forefront of the COVID-19 crisis as the first COVID-19 patient was traced on March 7, 2020 (10). The COVID-19 outbreak in Bangladesh is increasing day by day as already 38 deaths of the total 803 confirmed cases are identified until April 13, 2020 (11).

The most practical available solution to prevent the spread of the virus is to limit the community activities between people to prevent infection through the government's action rules (12). According to WHO (2020), social distance and selfisolation; and lockdown are two important nationwide social measures (9). The government of the people's republic of Bangladesh has adapted social distancing initiatives for two weeks from March 26 and is extended up to April $25(8,13)$. The country is completely locked up except hospitals, kitchen markets, drugstores, and other emergency services. During the lockdown period, residents are advised to stay home and not to leave home without emergent needs. There are limited public transportation, limited banking services, and Bangladesh Armed Forces are assisting the district 
Table 1. Distribution of knowledge, attitude and preventive practices toward COVID-19

\begin{tabular}{|c|c|c|c|}
\hline \multirow{2}{*}{$\begin{array}{c}\text { Question/statement (True/False) } \\
\text { Knowledge about COVID-19 }\end{array}$} & \multicolumn{3}{|c|}{ Response } \\
\hline & True & False & Don't Know \\
\hline Fever, fatigue, dry cough and shortness of breath are symptoms of COVID-19 (True) & $413(93.7)$ & $13(2.9)$ & $15(3.4)$ \\
\hline If one gets cold, cough or fever he/she is COVID-19 infected (False) & $12(2.7)$ & $406(92.1)$ & $23(5.2)$ \\
\hline The best way to prevent COVID-19 is to avoid the crowd and staying at home (True) & $422(95.7)$ & $13(2.9)$ & $6(1.4)$ \\
\hline Children and young boys/girls have no risk of death due to COVID-19 (False) & $33(7.5)$ & $392(88.9)$ & $16(3.6)$ \\
\hline If a crowd happens due to religious purpose there is no chance of COVID-19 spreading (False) & $14(3.2)$ & $412(93.4)$ & $15(3.4)$ \\
\hline COVID-19 can only go inside the body through the nose but not through eyes and mouth (False) & $23(5.2)$ & $396(89.8)$ & $22(5)$ \\
\hline Who looks healthy and has no cough or fever can't spread COVID-19 (False) & $44(10)$ & $358(81.2)$ & $39(8.8)$ \\
\hline Overall knowledge score $($ mean \pm SD) & \multicolumn{3}{|c|}{$6.35 \pm 1.16$} \\
\hline Attitude toward COVID-19 & Yes & \multicolumn{2}{|r|}{ No } \\
\hline Do you think the COVID-19 situation will stay under control? & \multicolumn{2}{|l|}{$184(41.7)$} & $257(58.3)$ \\
\hline Preventive practices toward COVID-19 & \multicolumn{2}{|l|}{ Yes } & No \\
\hline Staying home during the lockdown & \multicolumn{2}{|l|}{$411(93.2)$} & $30(6.8)$ \\
\hline Washing hands with soap or other anti-viral materials when returning the home & \multicolumn{2}{|l|}{435 (98.6) } & $6(1.4)$ \\
\hline Wearing masks when going outside the home & \multicolumn{2}{|l|}{$403(91.4)$} & $38(8.6)$ \\
\hline Maintaining safe distance with people (3 feet) when going outside the home & $384(87.1)$ & & $57(12.9)$ \\
\hline Overall practice score $($ mean \pm SD) & \multicolumn{3}{|c|}{$3.70 \pm 0.62$} \\
\hline
\end{tabular}

NB: SD=Standard Deviation

administration to combat COVID-19 situation through ensuring social distancing (14).

Currently, there is no treatment or vaccine against COVID19 , prevention of epidemic is not only the grand but the mere option (15). After all, World Health Organization (WHO) offers the most effective preventive measures: maintain physical distance (minimum 3 feet or 1 meter) from other persons; the hands must be cleaned immediately after contact with the respiratory tract; avoid touching eyes, nose and mouth frequently; regular cleaning and disinfection of environmental and other frequently touched surfaces; improve living space airflow by opening as many windows and doors as possible; fever, cough, and difficulty in breathing, seek immediate treatment (16-18).

Since no proven vaccine/medicine is available for COVID-19 and Bangladesh is a densely populated country so this type of highly contagious disease can be very lugubrious for the country. In this study, we investigated the knowledge, attitude and preventive practices during the rapid outbreak of COVID19 among Bangladeshi internet users.

\section{MATERIALS AND METHODS}

\section{Design of the Study}

The web-based cross-sectional study was carried out from April 7 to April 10, 2020, among Bangladeshi internet users. Since the country is maintaining a lockdown and restriction of movement to minimize COVID-19 spreading so it was the best available method to the authors to conduct the study using a convenience web-based survey. A self-reported structured questionnaire was prepared using the Google forms and the link was shared through email, Facebook groups, and other authors' networks. The Cronbach's alpha for the questionnaire is 0.64 indicating the questionnaire is a valid and reliable tool to assess the study purpose. The eligibility criteria to participate in the survey was to be a Bangladeshi internet user of age 18 years or above, understanding the study purpose, and willingness to voluntary participation. Each of the participants was explained the purpose of the study prior to attending the survey and only those agreed to the consent of voluntary willingness participated in the survey. The original questionnaire was written using the Bengali language which was further translated to English for preparing the study report. The survey was web-based and totally relied on the voluntary participation of all the eligible respondents so no prior sample size was calculated yet 441 valid samples were collected during the survey period.

\section{Measures}

The self-reported questionnaire consisted of demographic characteristics, respondent's knowledge, attitude, and preventive practices toward COVID-19. The questionnaire was divided into three different sections where the first section consists of demographic characteristics such as age, sex, education, marital status, occupation, residence type, and division of the respondent. The second section consisted of both knowledge and attitude toward COVID-19. A total of seven knowledge related questions were prepared and the respondent had to choose between a true/false or don't know option for these questions. 1 point was assigned for each correct answer and 0 was assigned for an incorrect/unknown answer. The third section consisted of four preventive practices for COVID-19. Both attitude and preventive practices were answered in a yes/no scale. For each preventive practice, 1 point was assigned and 0 for non-practice. Table 1 displays the translated knowledge, attitude and preventive practicerelated questions among those knowledge and practice related questions were developed using information from the World Health Organization's COVID-19 advice for the public (18).

\section{Statistical Analysis}

The data was analyzed using Statistical Package for Social Science (SPSS) version 23 software. Frequency, percentage and mean scores were calculated under descriptive analysis. The association between the different response and participants demographic characteristics were tested using ttest, one-way ANOVA or Chi-square test as appropriate. Under a multivariate technique to identify associated factors with the response, both linear regression and binary logistic regression were performed. We used stepwise backward likelihood ratio method for both the regression analysis. The prior level of significance was set to 0.05 (two-tailed). 
Table 2. Univariate and Bivariate characteristics with chi-square test for respondents' attitude toward COVID-19

\begin{tabular}{|c|c|c|c|c|c|c|c|c|}
\hline \multirow{3}{*}{\multicolumn{2}{|c|}{ Categories }} & \multirow{3}{*}{$\begin{array}{c}\text { Count } \\
(\%)\end{array}$} & \multicolumn{4}{|c|}{ Do you think the COVID-19 situation will stay under control } & \multirow{3}{*}{$\chi^{2}$} & \multirow{3}{*}{$P$ value } \\
\hline & & & \multicolumn{2}{|c|}{ No } & \multicolumn{2}{|c|}{ Yes } & & \\
\hline & & & Count & Percentage & Count & Percentage & & \\
\hline \multirow{2}{*}{ Age } & $18-29$ & $378(85.7)$ & 229 & $60.6 \%$ & 149 & $39.4 \%$ & \multirow{2}{*}{5.78} & \multirow{2}{*}{$0.016^{\star *}$} \\
\hline & 30 and above & $63(14.3)$ & 28 & $44.4 \%$ & 35 & $55.6 \%$ & & \\
\hline \multirow{2}{*}{ Sex } & Male & $303(68.7)$ & 186 & $61.4 \%$ & 117 & $38.6 \%$ & \multirow{2}{*}{3.85} & \multirow{2}{*}{$0.050^{\star \star}$} \\
\hline & Female & $138(31.3)$ & 71 & $51.4 \%$ & 67 & $48.6 \%$ & & \\
\hline \multirow{2}{*}{ Education } & Bachelor or higher & $304(68.9)$ & 193 & $63.5 \%$ & 111 & $36.5 \%$ & \multirow{2}{*}{10.93} & \multirow{2}{*}{$<0.01^{\star \star}$} \\
\hline & Up to HSC & $137(31.1)$ & 64 & $46.7 \%$ & 73 & $53.3 \%$ & & \\
\hline \multirow{2}{*}{ Occupation } & Student & $281(63.7)$ & 169 & $60.1 \%$ & 112 & $39.9 \%$ & \multirow{2}{*}{1.11} & \multirow{2}{*}{0.292} \\
\hline & Others & $160(36.3)$ & 88 & $55.0 \%$ & 72 & $45.0 \%$ & & \\
\hline \multirow{2}{*}{ Residence type } & Urban & $333(75.5)$ & 202 & $60.7 \%$ & 131 & $39.3 \%$ & \multirow{2}{*}{3.18} & \multirow{2}{*}{$0.075^{*}$} \\
\hline & Rural & $108(24.5)$ & 55 & $50.9 \%$ & 53 & $49.1 \%$ & & \\
\hline \multirow{2}{*}{ Marital status } & Married & $95(21.5)$ & 47 & $49.5 \%$ & 48 & $50.65 \%$ & \multirow{2}{*}{3.86} & \multirow{2}{*}{$0.049^{\star *}$} \\
\hline & Unmarried & $346(78.5)$ & 210 & $60.7 \%$ & 136 & $39.3 \%$ & & \\
\hline \multirow{3}{*}{ Division } & Khulna & $222(50.3)$ & 134 & $60.4 \%$ & 88 & $39.6 \%$ & \multirow{3}{*}{1.09} & \multirow{3}{*}{0.580} \\
\hline & Dhaka & $114(25.9)$ & 66 & $57.9 \%$ & 48 & $42.1 \%$ & & \\
\hline & Others & $105(23.8)$ & 57 & $54.3 \%$ & 48 & $45.7 \%$ & & \\
\hline
\end{tabular}

Note: ${ }^{*}$ indicates the Chi-square statistic is significant at the 0.1 level and ${ }^{\star \star}$ indicates significant at the 0.05 level

Table 3. Distribution of COVID-19 Knowledge score and preventive practice score among Bangladeshi internet users

\begin{tabular}{|c|c|c|c|c|c|c|c|}
\hline \multicolumn{2}{|c|}{ Characteristics } & \multirow{3}{*}{$\begin{array}{c}\begin{array}{c}\text { Knowledge Score } \\
\text { (mean } \pm \text { SD) }\end{array} \\
6.43 \pm 1.05 \\
5.86 \pm 1.62\end{array}$} & \multirow{3}{*}{$\begin{array}{c}\text { F value } \\
13.432\end{array}$} & \multirow{3}{*}{$\begin{array}{l}\text { P value } \\
<0.01^{\star \star}\end{array}$} & \multirow{3}{*}{$\begin{array}{c}\begin{array}{c}\text { Practice Score } \\
\text { (mean } \pm \text { SD) }\end{array} \\
3.73 \pm 0.59 \\
3.54 \pm 0.78\end{array}$} & \multirow{3}{*}{$\begin{array}{c}\text { F value } \\
5.116\end{array}$} & \multirow{3}{*}{$\frac{\text { P value }}{0.024^{* \star}}$} \\
\hline \multirow{2}{*}{ Age } & $18-29$ & & & & & & \\
\hline & 30 and above & & & & & & \\
\hline \multirow{2}{*}{ Sex } & Male & $6.44 \pm 1.01$ & \multirow{2}{*}{6.143} & \multirow{2}{*}{$0.014^{\star \star}$} & $3.68 \pm 0.62$ & \multirow{2}{*}{1.746} & \multirow{2}{*}{0.187} \\
\hline & Female & $6.14 \pm 1.42$ & & & $3.76 \pm 0.62$ & & \\
\hline \multirow{2}{*}{ Education } & Bachelor or higher & $6.54 \pm 0.77$ & \multirow{2}{*}{28.557} & \multirow{2}{*}{$<0.01^{\star \star}$} & $3.73 \pm 0.54$ & \multirow{2}{*}{2.379} & \multirow{2}{*}{0.124} \\
\hline & Up to HSC & $5.92 \pm 1.67$ & & & $3.64 \pm 0.77$ & & \\
\hline \multirow{2}{*}{ Occupation } & Student & $6.44 \pm 0.88$ & \multirow{2}{*}{5.155} & \multirow{2}{*}{$0.024^{\star \star}$} & $3.74 \pm 0.53$ & \multirow{2}{*}{2.794} & \multirow{2}{*}{$0.095^{\star}$} \\
\hline & Others & $6.18 \pm 1.52$ & & & $3.64 \pm 0.75$ & & \\
\hline \multirow{2}{*}{ Residence type } & Urban & $6.43 \pm 1.01$ & \multirow{2}{*}{6.444} & \multirow{2}{*}{$0.011^{\star \star}$} & $3.73 \pm 0.57$ & \multirow{2}{*}{3.136} & \multirow{2}{*}{$0.077^{\star}$} \\
\hline & Rural & $6.10 \pm 1.52$ & & & $3.61 \pm 0.76$ & & \\
\hline \multirow{2}{*}{ Marital status } & Married & $5.88 \pm 1.67$ & \multirow{2}{*}{20.038} & \multirow{2}{*}{$<0.01^{\star \star}$} & $3.57 \pm 0.82$ & \multirow{2}{*}{5.730} & \multirow{2}{*}{$0.017^{\star \star}$} \\
\hline & Unmarried & $6.47 \pm 0.94$ & & & $3.74 \pm 0.55$ & & \\
\hline \multirow{3}{*}{ Division } & Khulna & $6.39 \pm 0.99$ & \multirow{3}{*}{2.042} & \multirow{3}{*}{0.131} & $3.72 \pm 0.53$ & \multirow{3}{*}{1.671} & \\
\hline & Dhaka & $6.45 \pm 1.21$ & & & $3.75 \pm 0.62$ & & 0.189 \\
\hline & Others & $6.15 \pm 1.41$ & & & $3.61 \pm 0.78$ & & \\
\hline
\end{tabular}

Note: * indicates the statistic is significant at the 0.1 level and ${ }^{\star *}$ indicates significant at the 0.05 level, SD = Standard Deviation

\section{RESULTS}

A total of 441 respondents willingly participated in the survey. Table 2 reveals that the majority of the respondents are male (68.7\%), of age 18 to 29 (85.7\%), completed a bachelor or higher education $(68.9 \%)$, student $(63.7 \%)$, reside in urban areas (75.5\%), unmarried (78.5\%) and are from Khulna Division $(50.3 \%)$ of Bangladesh.

From Table 1 it is found that the majority of the participants know the symptoms of the COVID-19 (93.7\%) and don't forcefully consider all fever, cough or cold symptoms as COVID-19 (92.1\%). 95.7\% of the respondents know that the best way to prevent COVID-19 spreading is by staying home and avoiding the crowd. Although the percentage is a bit lower than previous correct knowledge percentage, the majority knows COVID-19 can be fatal even for children \& young and how it enters into the human body ( $88.9 \%$ and $89.8 \%$, respectively).

Most of the respondents have no religious prejudice about COVID-19 spreading (93.4\%). 10\% of the respondents answered wrongly and $8.8 \%$ reported that they don't know that a person looks healthy, doesn't have fever, cough, and cold can also spread COVID-19 which is the highest among all wrong answer and ignorance. The overall knowledge score was $6.35 \pm 1.16$ (mean \pm standrd deviation).

Among the respondents, $41.7 \%$ are hopeful that the COVID19 situation will stay under control but the majority are thinking otherwise (58.3\%).

The majority of the respondents are staying home, wearing a mask and keeps safe distance when goes outside (93.2\%, $91.4 \%$, and $87.1 \%$, respectively). Almost all of the participants $(98.6 \%)$ washes their hands with soap or anti-viral materials when they return home. The results of the survey questionnaire consisting of knowledge, attitude and preventive practices toward COVID-19 are summarized in Table 1.

From Table 2 we see that age, sex, education, and marital status are significantly associated with a positive attitude toward COVID-19 ( $\mathrm{P}=0.016, \mathrm{P}=0.050, \mathrm{P}<0.01$, and $\mathrm{P}=0.049$, respectively). Respondents who are optimistic are mostly age 30 and above (55.6\%), female (48.6\%), completed up to HSC (53.3\%), and married (50.65\%).

Table 3 reveals that the mean knowledge score about COVID-19 differs significantly across different age groups $(P<0.01)$, sex $(P=0.014)$, education $(P<0.01)$, occupation $(P=0.024)$, residence type $(P=0.011)$, and marital status $(P<0.01)$. Also, the mean score of COVID-19 preventive practice 
Table 4. Multiple linear regression output showing factors significantly related to higher COVID-19 knowledge score and preventive practice score using the backward Likelihood Ratio method

\begin{tabular}{|c|c|c|c|c|}
\hline Factors & $\boldsymbol{\beta}$ & Standard Error & $\mathbf{t}$ & P value \\
\hline \multicolumn{5}{|l|}{ Knowledge score for COVID-19 } \\
\hline Intercept & 5.111 & 0.175 & 29.144 & $<0.01^{\star \star}$ \\
\hline Marital status (Unmarried vs. married) & 0.605 & 0.126 & 4.780 & $<0.01^{\star \star}$ \\
\hline Place of residence (Urban vs. Rural) & 0.274 & 0.121 & 2.262 & $0.024^{* \star}$ \\
\hline Education (Bachelor and higher vs. Up to HSC) & 0.658 & 0.115 & 5.716 & $<0.01^{\star \star}$ \\
\hline Division (Khulna vs. others) & 0.200 & 0.106 & 1.876 & $0.061^{*}$ \\
\hline \multicolumn{5}{|l|}{ Practice score for COVID-19 } \\
\hline Intercept & 3.428 & 0.085 & 40.318 & $<0.01^{\star \star}$ \\
\hline Marital status (Unmarried vs. married) & 0.193 & 0.072 & 2.683 & $<0.01^{\star \star}$ \\
\hline Education (Bachelor and higher vs. Up to HSC) & 0.122 & 0.064 & 1.899 & $0.058^{\star}$ \\
\hline Sex (Female vs. male) & 0.127 & 0.065 & 1.960 & $0.051^{\star}$ \\
\hline
\end{tabular}

Note: * indicates the statistic is significant at the 0.1 level and ${ }^{\star *}$ indicates significant at the 0.05 level

Table 5. Logistic regression output showing factors significantly related to the attitude that COVID-19 will be under control and different practices toward COVID-19 using the stepwise backward Likelihood Ratio method

\begin{tabular}{|c|c|c|c|c|c|c|}
\hline \multirow{2}{*}{\multicolumn{2}{|c|}{ Categories }} & \multirow{2}{*}{ Estimates } & \multirow{2}{*}{ AOR } & \multirow{2}{*}{ P value } & \multicolumn{2}{|c|}{ 95\% C.I. for AOR } \\
\hline & & & & & Lower & Upper \\
\hline \multicolumn{7}{|c|}{ Attitude: The COVID-19 situation will stay under control } \\
\hline \multirow{2}{*}{ Age } & $18-29(\mathrm{RC})$ & & & & & \\
\hline & 30 and above & .675 & 1.96 & $0.016^{\star \star}$ & 1.13 & 3.41 \\
\hline \multirow{2}{*}{ Sex } & Male (RC) & & & & & \\
\hline & Female & .374 & 1.45 & $0.084^{*}$ & $1.02^{\mathrm{a}}$ & $2.08^{\mathrm{a}}$ \\
\hline \multirow{2}{*}{ Education } & Bachelor \& higher (RC) & & & & & \\
\hline & Up to HSC & .609 & 1.84 & $<0.01^{\star \star}$ & 1.21 & 2.80 \\
\hline \multirow{3}{*}{ Residence type } & Urban (RC) & & & & & \\
\hline & Rural & .436 & 1.55 & $0.059^{\star}$ & $1.06^{\mathrm{a}}$ & $2.26^{\mathrm{a}}$ \\
\hline & Constant & -.855 & .43 & $<0.01^{\star \star}$ & & \\
\hline \multicolumn{7}{|c|}{ Practice 1: Staying home during the lockdown } \\
\hline \multirow{3}{*}{ Age } & 30 and above (RC) & & & & & \\
\hline & $18-29$ & 1.592 & 4.92 & $<0.01^{\star \star}$ & 2.40 & 9.90 \\
\hline & Knowledge score & .548 & 1.73 & $<0.01^{\star \star}$ & 1.43 & 2.09 \\
\hline \multicolumn{7}{|c|}{ Practice 3: Wearing masks when going outside the home } \\
\hline & Knowledge score & .435 & 1.54 & $<0.01^{\star \star}$ & 1.25 & 1.77 \\
\hline \multicolumn{7}{|c|}{ Practice 4: Maintaining safe distance with people (3 feet) when going outside the home } \\
\hline \multirow{2}{*}{ Sex } & Male (RC) & & & & & \\
\hline & Female & .726 & 2.07 & $0.040^{\star \star}$ & 1.16 & 3.69 \\
\hline
\end{tabular}

Note: C.I. $=$ Confidence Interval, AOR=Adjusted Odds Ratio, RC= reference category, ${ }^{\star}$ indicates the statistic is significant at the 0.1 level, ${ }^{\star \star}$ indicates significant at the 0.05 level, and ${ }^{a}$ indicates $90 \%$ confidence interval

varies across different age groups $(P=0.024)$ and marital status $(P=0.017)$. From the linear regression analysis, we see that the marital status of unmarried (vs. married, $\beta=0.605 ; \mathrm{P}<0.01$ ), bachelor or higher education (vs. up to HSC, $\beta=0.658$; $\mathrm{P}<0.01$ ) and urban residence type (vs. rural, $\beta=0.274 ; \mathrm{P}=0.024$ ) are significantly associated with higher knowledge score (Table 4). Also, the marital status of unmarried (vs. married, $\beta=0.193$; $\mathrm{P}<0.01)$ is significantly associated with higher preventive practice score (PPS) (Table 4).

Table 5 demonstrates that, respondent of age 30 and above are more optimistic (Adjusted Odds Ratio [AOR] $=1.96$, 95\% Confidence Interval $[\mathrm{Cl}], 1.13$ to $3.41 ; \mathrm{P}=0.016$ ) compared to respondent of age 18-29. A respondent who completed up to HSC is $1.84(95 \% \mathrm{Cl}, 1.21$ to 2.80 ; $\mathrm{P}<0.01)$ times more optimistic compared to bachelor or higher educated respondent. Respondent of age group 18-29 are more likely to stay home (AOR=4.92, 95\% Cl, 2.40 to $9.90 ; \mathrm{P}<0.01$ ) compared to 30 and above age group. For 1 unit change in the knowledge score the likelihood of staying home and wearing mask increases by 1.73 $(95 \% \mathrm{Cl}, 1.43$ to $2.09 ; \mathrm{P}<0.01)$ and $1.54(95 \% \mathrm{Cl}, 1.25$ to 1.77 ; $\mathrm{P}<0.01)$ times respectively. It is seen that females are more likely to maintain a safe distance ( 3 feet) when going outside compared to males with $\mathrm{AOR}=2.07(95 \% \mathrm{Cl}, 1.16$ to 3.69 ; $\mathrm{P}=0.04)$.

Additionally, the Spearman correlation test showed a positive correlation between the COVID-19 knowledge score and PPS ( $r=0.291, P<0.01)$. The finding implies higher the knowledge score about COVID-19 the higher the PPS; lower the knowledge score the lower the PPS. So a good knowledge is important for a better practice toward COVID-19.

\section{DISCUSSION}

From the most recent available information, this is so far the maiden study to investigate knowledge, attitude and preventive practices toward COVID-19 in Bangladesh. The study is dominated by the male (68.7\%) and well educated $(68.9 \%)$ respondents where the overall correct knowledge is $63.3 \%$ and complete practice prevalence is $76.9 \%$.

We have found that most of the respondents have a negative attitude toward COVID-19 situation control. A possible explanation of this type of attitude can be due to the rapid spreading of the disease even in developed countries like Italy and the United States of America where over 15 thousand 
death and over 1 lakh total infected cases have been reported (11). This finding coincides with the attitude of respondents of KSA toward MERS-CoV (19), but contradicts the attitude of Chinese (20) and Indian (21) respondents toward COVID-19 and Ebola respectively.

We have seen that young people (age 18-29) are more likely to stay home (preventive practice toward COVID-19) than middle and older (age 30 and above) which was totally reverse against Dengue (22).

This study found knowledge score has a direct association with wearing a mask when going outside and staying home. A study in China reported a similar association between knowledge score and wearing masks (20). This study reports the knowledge score significantly varies with different age groups, gender, education, occupation, marital status and residence type which partially coincides with previous studies $(20,23)$.

We found that overall higher knowledge score is associated with higher preventive practices toward COVID-19, a similar association between the knowledge about the disease and preventive practices were reported in KSA on MERS-CoV (19), Pakistan on Dengue (22) (a viral disease), and in China (20) on COVID-19. Countries like Nicaragua (24) and the Philippines (25) have already taken an initiative to increase the spreading of knowledge to prevent infectious disease and its transmission.

In conclusion, we believe that the study will inspire the healthcare authorities, and media to spread more COVID-19 related accurate knowledge which ultimately results in better preventive practices toward COVID-19. Since no proven medicine is invented yet, so the best way is to minimize the spreading by maximizing knowledge and preventive practices toward COVID-19.

\section{ACKNOWLEDGEMENT}

The authors are grateful to all respondents for their voluntary participation in the study.

\section{REFERENCES}

1. Spagnuolo G, De Vito D, Rengo S, Tatullo M. COVID-19 Outbreak: An Overview on Dentistry. 2020: 2094. https://doi.org/10.3390/ijerph17062094 PMid:32235685 PMCid:PMC7143628

2. Chen N, Zhou M, Dong X, Qu J, et al. Epidemiological and clinical characteristics of 99 cases of 2019 novel coronavirus pneumonia in Wuhan, China: a descriptive study. The Lancet. 2020 Feb 15;395(10223):507-13. https://doi.org/10.1016/S0140-6736(20)30211-7

3. Novel CP. The epidemiological characteristics of an outbreak of 2019 novel coronavirus diseases (COVID-19) in China. Zhonghua liu xing bing xue za zhi= Zhonghua liuxingbingxue zazhi. 2020 Feb 17;41(2):145. Available at: https://cdn.onb.it/2020/03/COVID-19.pdf.pdf

4. World Health Organization. Clinical management of severe acute respiratory infection (SARI) when COVID-19 disease is suspected: interim guidance, 13 March 2020. World Health Organization; 2020. Available at: https://apps.who.int/ iris/bitstream/handle/10665/331446/WHO-2019-nCoVclinical-2020.4-chi.pdf
5. Malik M, Elkholy AA, Khan W, Hassounah S, et al. Middle East respiratory syndrome coronavirus: current knowledge and future considerations. EMHJ-Eastern Mediterranean Health Journal. 2016;22(7):533-42. https://doi.org/ 10.26719/2016.22.7.533

6. Meng L, Hua F, Bian Z. Coronavirus disease 2019 (COVID19): emerging and future challenges for dental and oral medicine. Journal of Dental Research. 2020 Mar 12:0022034520914246. https://doi.org/10.1177/002203452 0914246 PMid:32162995 PMCid:PMC7140973

7. Peng X, Xu X, Li Y, Cheng L, Zhou X, Ren B. Transmission routes of 2019-nCoV and controls in dental practice. International Journal of Oral Science. 2020 Mar 3;12(1):1-6. https://doi.org/10.1038/s41368-020-0075-9 PMid:32127517 PMCid:PMC7054527

8. Islam MD. COVID-19 and Bangladesh: A study of the public perception on the measures taken by the government. https://doi.org/10.13140/RG.2.2.30042.49608

9. World Health Organization. WHO Director-General's opening remarks at the media briefing on COVID-19-11 March 2020. Geneva, Switzerland. 2020 Mar. Available at: https://www.who.int/dg/speeches/detail/who-directorgeneral-s-opening-remarks-at-the-media-briefing-oncovid-19---11-march-2020

10. Hossain A, Rana J, Benzadid S, Ahsan GU. Covid-19 and Bangladesh. 2020 March https://doi.org/10.13140/ RG.2.2.33293.08161

11. Worldometers.info, Dover, Delaware, U.S.A [cited 13 April 2020]. Available at: http://www.worldometers.info/ coronavirus/\#countries

12. Wu Z, McGoogan JM. Characteristics of and important lessons from the coronavirus disease 2019 (COVID-19) outbreak in China: summary of a report of 72314 cases from the Chinese Center for Disease Control and Prevention. Jama. 2020 Feb 24. https://doi.org/10.1001/ jama.2020.2648 PMid:32091533

13. Vince G. The world's largest refugee camp prepares for covid-19. Bmj. 2020 Mar 26;368. https://doi.org/10.1136/ bmj.m1205 PMid:32217520

14. World Health Organization (WHO) Coronavirus disease (COVID-2019) situation reports-6, 2020 [cited 12 April 2020]. Available at: https://www.who.int/bangladesh/emergen cies/coronavirus-disease-(covid-19)-update/coronavirusdisease-(covid-2019)-bangladesh-situation-reports

15. Heymann DL, Shindo N. COVID-19: what is next for public health?. The Lancet. 2020 Feb 22;395(10224):542-5. https://doi.org/10.1016/S0140-6736(20)30374-3

16. World Health Organization. Rational use of personal protective equipment for coronavirus disease ( COVID-19) and considerations during severe shortages: interim guidance, 6 April 2020. World Health Organization; 2020. Available at: https://apps.who.int/iris/bitstream/handle/ 10665/331215/WHO-2019-nCov-IPCPPE_use-2020.1-eng. pdf

17. World Health Organization. Advice on the use of masks in the community, during home care and in health care settings in the context of the novel coronavirus (2019-nCoV) outbreak: interim guidance. Available at: https://apps.who.int/iris/bitstream/handle/10665/331215/ WHO-2019-nCov-IPCPPE_use-2020.1-eng.pdf

18. World Health Organization (WHO). Coronavirus disease (COVID-19) advice for the public. [cited 12 April 2020]. Available at: https://www.who.int/emergencies/diseases/ novel-coronavirus-2019/advice-for-public 
19. Nour MO, Babilghith AO, Natto HA, Al-Amin FO, Alawneh SM. Knowledge, attitude and practices of healthcare providers towards MERS-CoV infection at Makkah hospitals, KSA. Int Res J Med Med Sci. 2015 Oct;3(4):103-2. Available at: https://pdfs.semanticscholar.org/6b51/ 4d5adb91b32c89857e9c38d5ae98cf854ac8.pdf

20. Zhong BL, Luo W, Li HM, Zhang QQ, Liu XG, Li WT, Li Y. Knowledge, attitudes, and practices towards COVID-19 among Chinese residents during the rapid rise period of the COVID-19 outbreak: a quick online cross-sectional survey. International Journal of Biological Sciences. 2020;16(10):1745. https://doi.org/10.7150/ijbs.45221 PMid:32226294 PMCid:PMC7098034

21. Ahmad A, Khan MU, Jamshed SQ, Kumar BD, Kumar GS, Reddy PG, Ajmera S. Are healthcare workers ready for Ebola? An assessment of their knowledge and attitude in a referral hospital in South India. The Journal of Infection in Developing Countries. 2016 Aug 2;10(07):747-54. https://doi.org/10.3855/jidc.7578 PMid:27482807

22. Rana MS, Shakil MS. Knowledge, Attitude and Practice on Dengue Fever Transmission Among Urban and Periurban Residents of Dhaka City, Bangladesh. Tropical Medicine Journal. 3(2). https://doi.org/10.22146/tmj.5862
23. Hafeez F, Akram W, Suhail A, Arshad M. Knowledge and attitude of the public towards dengue control in urban and rural areas of Punjab. Pakistan Journal of Zoology. 2012 Feb 1;44(1). Available at: http://www.zsp.com.pk/pdf44/ 15-21\%20_3_\%20PJZ-383-10[1]\%20proof\%20corrected. pdf

24. Mayers G. Education and community sensitization are the keys to preventing dengue. Geneva: International Federation of Red Cross and Red Crescent Societies. 2013. Available at: https://www.ifrc.org/en/news-and-media/ news-stories/americas/nicaragua/education-and-com munity-sensitization-are-the-key-to-preventing-dengue63750/

25. Yboa BC, Labrague LJ. Dengue knowledge and preventive practices among rural residents in Samar province, Philippines. American Journal of Public Health Research. 2013 Apr;1(2):47-52. https://doi.org/10.12691/ajphr-1-2-2 